\title{
Health assessment of the pink land iguana, Conolophus marthae
}

\author{
Gabriele Gentile ${ }^{1,{ }^{\ddagger}}$, Giuliano Colosimo $0^{1,2,{ }^{\ddagger}}$, Carlos A. Vera ${ }^{3}$, Glenn P. Gerber ${ }^{2}$, Hans \\ Westermeyer ${ }^{4}$, Christian Sevilla ${ }^{3}$, Gregory A. Lewbart ${ }^{4,5,6, *}$
}

${ }^{1}$ Department of Biology, Tor Vergata University, Via della Ricerca Scientifica, Rome 00133, Italy

${ }^{2}$ San Diego Zoo Wildlife Alliance, 15600 San Pasqual Valley Road, Escondido, CA 92027

${ }^{3}$ Dirección Parque Nacional Galápagos, Puerto Ayora, Galápagos, Ecuador

${ }^{4}$ North Carolina State University College of Veterinary Medicine, 1060 William Moore Drive, Raleigh, NC 27606,

USA

${ }^{5}$ Universidad San Francisco de Quito USFQ, Colegio de Ciencias Biológicas y Ambientales, Casilla Postal 17-1200-

841, Quito 170901, Ecuador

${ }^{6}$ Galápagos Science Center GSC, Av. Alsacio Northia, Isla San Cristobal, Galápagos, Ecuador

${ }^{\ddagger}$ These authors contributed equally to the manuscript

Orcid ID:

- Giuliano Colosimo: 0000-0002-0485-9758

- Gregory Lewbart: 0000-0003-0716-1387

- Gabriele Gentile: 0000-0002-1045-6816

*Corresponding author:

Email: greg lewbart@ncsu.edu 


\section{Abstract}

The pink land iguana, Conolophus marthae, is one of four species of iguanas (three terrestrial and one marine) in the Galápagos Islands, and the only one listed as critically endangered by the IUCN. The species can only be found on the north-west slopes of the highest volcano on the island of Isabela and was first described to science in 2009. As part of a population telemetry study, a health assessment was authorized by the Galápagos National Park. Wild adult iguanas were captured on Wolf Volcano in September 2019 and April 2021 to record morphological and physiological parameters including body temperature, heart rate, body measurements, intraocular pressures, tear formation, and infrared iris images. Blood samples were also collected and analyzed. An i-STAT portable blood analyzer was used to obtain values for base excess in the extracellular fluid compartment (BEECF), glucose, hematocrit, hemoglobin, ionized calcium (iCa), partial pressure of carbon dioxide $\left(\mathrm{pCO}_{2}\right)$, partial pressure of oxygen $\left(\mathrm{pO}_{2}\right)$, percent oxygen saturation $\left(\mathrm{sO}_{2} \%\right), \mathrm{pH}$, potassium ( $\left.\mathrm{K}\right)$, and sodium ( $\mathrm{Na}$ ). Standard laboratory hematology techniques were employed for packed-cell-volume (PCV) determination. When possible, data were compared to previously published and available data for the other Galápagos iguanas. The results reported here provide baseline values that may be useful in detecting changes in health status among pink land iguanas affected by climate change, invasive species, anthropogenic threats, or natural disturbances. 


\section{Introduction}

The Galápagos pink land iguana, Conolophus marthae, was first sighted on Wolf Volcano (WV hereafter), Isabela Island, in 1986, but was not described to science as a separate and unique species until 2009 (Gentile \& Snell, 2009). The species is under the protection of Galápagos National Park Directorate (GNPD) and listed in Appendix II of the Convention on International Trade in Endangered Species of Wild Fauna and Flora (CITES, Appendices I, II and III, 2021). It is classified as critically endangered by the IUCN Red List of Threatened Species (Gentile, 2012). Among the major threats for the species we recognize: a single and very small population (200 $<\mathrm{N}<300$ adult individuals); small area of distribution estimated at no more than $25 \mathrm{~km}^{2}$; lack of recruitment, with no hatchlings and very few juveniles observed since 2005; introduced alien species such as cats and rats; and volcanic eruption (WV is an active volcano that last erupted in 2015). With such a small population, these animals are at risk of extinction, from both natural and anthropogenic events. Although information on the natural history and biology of $C$. marthae has been accumulating since its description to science (Gentile \& Snell, 2009; Gentile et al., 2009; Fabiani et al., 2011; Gentile, 2012; Gentile et al., 2016; Di Giambattista et al., 2018; Colosimo et al., 2020), very little is known about the species' overall health and baseline medical parameters. This called for urgent action aimed at providing data about the health status of this flagship species.

Peripheral blood biochemical, blood gas, and hematology parameters are useful for assessing lizard health (Geffre et al., 2009; Klaphake et al., 2017; Arguedas et al., 2018; Lewbart et al., 2019). It is important to establish and publish species-specific baseline physiological parameters for healthy individuals since disease, injury, pollutants, starvation and other factors can result in blood value perturbations. Several reference intervals have been established for iguanids and include: Conolophus pallidus and C. subcristatus (Lewbart et al., 2019), Amblyrhynchus cristatus (Lewbart et al., 2015), Basiliscus plumifrons (Dallwig et al., 2010), Cyclura cychlura inornata (James et al., 2006), Cyclura ricordii (Maria et al., 2007), and Iguana iguana (Dennis et al., 2001; Divers et al., 1996; Harr et al., 2001; Hernandez-Divers et al., 2005; Wagner \& Wetzel, 1999). 
As part of a remote monitoring population study, a health assessment study for the pink iguanas was authorized by the GNPD. A detailed description of the satellite tracking study is beyond the scopes of this article, and we refer to Loreti and colleagues (2019 and 2020) for further information. Nevertheless, we took advantage of this study and proceeded in two ways: i) we sampled wild pink iguanas on WV, Isabela Island, in September 2019 and April 2021 to analyze blood chemistry and hematological parameters and establish an intra-specific baseline report of such parameters; ii) we collected all published blood chemistry data available for other Galápagos iguanas to perform, when possible, an inter-specific comparison of such parameters. For wild samples collected in 2019 and 2021 a complete veterinary health examination was performed. The examination included measurement of body temperature, heart rate, length, body weight, intraocular pressure, ocular tear production, collection of blood samples, ectoparasites, and, in some cases, feces. All procedures were in accordance with the ethics and animal handling protocols approved by the GNPD. In the current study, we report on the blood chemical analysis and status of clinically healthy wild adult Galápagos pink land iguanas. 


\section{Materials and Methods}

\section{Ethic statement}

This population health assessment was conducted on Wolf Volcano, Isabela Island, Galápagos archipelago (Ecuador), and was authorized by the Galápagos National Park Directorate (Permit \# PC-04-21 issued to G. Gentile). The techniques used during this health assessment were also approved by the University of Rome "Tor Vergata" ethics and animal handling protocol and the San Diego Zoo Wildlife Alliance IACUC. All procedures were carried out by a licensed veterinarian and author of this study (GL).

\section{Iguana capture, measurement, and sampling}

We captured, tagged, and sampled 15 and 27 adult pink iguana individuals during field expeditions conducted in September 2019 and April 2021, respectively. Individuals were captured in an area on WV comprising approximately $6 \mathrm{~km}^{2}$ at an altitude of 1600-1700 m. All iguanas were captured by hand or noose, either inside of or adjacent to their burrows. The animals were quickly transported to a field laboratory area (usually located within 10 meters of the capture site) for blood drawing, usually within 5 minutes from capture. A blood sample of approximately $2.5 \mathrm{~mL}$ was obtained from the coccygeal hemal arch of each iguana using a heparinized 22-gauge $3.8 \mathrm{~cm}$ needle attached to a $10.0 \mathrm{~mL}$ syringe. The blood was divided into sub-samples and stored in a field cooler kept refrigerated using icepacks. Once the blood sample was secured the animal was examined, measured, weighed, and a custom designed GPS tracker was attached (Loreti et al. 2019, 2020 for further details on the tracking devices).

Cloacal temperature and heart rate were recorded shortly after the blood was taken, and usually within 5 minutes of capture. Heart rate was recorded via a Doppler ultrasound probe (Parks Medical Electronics, Inc., Aloha, Oregon, USA) over the heart. An EBRO ${ }^{\circ}$ Compact $\mathrm{J} / \mathrm{K} / \mathrm{T} / \mathrm{E}$ thermocouple thermometer (model EW-91219-40; Cole-Parmer, Vernon Hills, Illinois, USA 60061) with a T-PVC epoxy-tipped 24 GA probe was used to determine core body temperature. Snout-vent length (SVL) and tail length (TL) were recorded with a flexible measuring tape and used to determine the total length. Body mass was measured with a digital scale $( \pm 0.1 \mathrm{~kg})$. The sex of the iguanas was determined by the presence or absence of 
hemipenes or by visually inspecting secondary sexual characteristics (presence/absence of femoral pores, size of the individual, prominence of nuchal crest). Prior to release, ectoparasite load was determined by counting the number of ticks as in Onorati and colleagues (2016). For each animal, a sample of ticks was collected and preserved in 70\% ethanol. In 2021 close inspection of all animals revealed populations of small red mites associated with the skin over the cranial trunk and shoulder areas. Samples were collected and preserved in $70 \%$ ethanol. Each animal was also scanned for the presence of a Passive-Integrated-Transponder (PIT) tag and checked for the presence of a brand. For never-before captured individuals a PIT tag was placed under the femoral skin of the right leg for long term identification and population monitoring.

A complete examination of the eyes was performed by a single evaluator (GAL). Within 15 minutes of capture, internal ocular pressure (IOP) measurements were taken of the left (IOP_L) and right (IOP_R) eye using a rebound tonometer (TonoVet ${ }^{\circledR}$, iCare, Tiolat, Helsinki, Finland). Intraocular pressures were measured on the Tonovet's $s^{\circledR}$ rebound tonometer on undefined patient setting (p). Disposable probes were used and changed between every patient. The tonometer was held in position perpendicular to the patient eye and approximately $5 \mathrm{~mm}$ from the corneal surface. Tear production was measured using the endodontic absorbent point paper test (EPPT) in all 15 iguanas sampled in 2019 but not for samples collected in 2021. Size 30, 40, and 45 endodontic paper points (Parallax ${ }^{\circledR}$ Veterinary Absorbent Paper Points) were used. The tapered end of the clean points was placed into the fornix in both the left and right eye. The paper was removed after 60 seconds and the length of moisture that was wicked on the point was measured with a millimeter ruler. External infrared

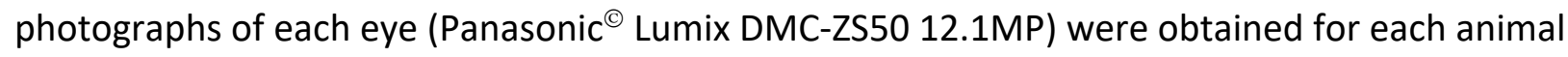
sampled in 2019 and reviewed for ocular abnormalities by a board-certified veterinary ophthalmologist (HW). Before releasing each animal in the exact location where it was caught, a unique ID number was painted on both flanks and the tip of the tail (to prevent recapture) using a non-toxic, washable white paint.

\section{Hematology parameters}


The blood samples were used for measuring various hematological parameters: approx. one drop was used for lactate analysis; approx. one drop for glucose analysis; about $0.1 \mathrm{~mL}$ was loaded into an i-STAT Clinical Analyzer (Heska Corporation, Fort Collins, Colorado, USA) utilizing Chem8 cartridges (see later in text for details); about $0.05 \mathrm{~mL}$ was used for centrifugation with a portable microcentrifuge (Eppendorf North America, Inc., centrifuge model 5424, 5 min. at $14,000 \mathrm{G}$ ) to determine packed cell volume (PCV) and total solids (TS). The PCV was determined by measuring the percentage of cellular material compared to plasma in the tubes. Two drops of plasma were placed on a refractometer (Ade Advanced Optics, Oregon City, Oregon 97045, USA) and the total solids values recorded. We additionally used approx. one drop of blood for making blood films on clean glass microscope slides (samples not yet analyzed).

The i-STAT Clinical Analyzer is a handheld, battery-powered, device that measures selected blood gas, biochemical, and hematology parameters using approx. $0.095 \mathrm{~mL}$ of noncoagulated whole blood. The following parameters were measured: base excess in the extracellular fluid compartment (BEECF), bicarbonate $\left(\mathrm{HCO}_{3}{ }^{-}\right)$, glucose, hematocrit, hemoglobin, ionized calcium (iCa), partial pressure of carbon dioxide $\left(\mathrm{pCO}_{2}\right)$, total carbon dioxide $\left(\mathrm{TCO}_{2}\right)$, partial pressure of oxygen $\left(\mathrm{pO}_{2}\right), \mathrm{pH}$, potassium $(\mathrm{K})$, and sodium $(\mathrm{Na})$. The i-STAT automatically produces temperature corrected values for $\mathrm{pCO}_{2}, \mathrm{pH}$ and $\mathrm{pO}_{2}$ once the animal's body temperature is entered. Blood lactate was determined using a portable Lactate Plus ${ }^{\mathrm{TM}}$ analyzer (Nova Biomedical, Waltham, Massachusetts, 02454 USA). A glucometer (Accu-Check ${ }^{\circledR}$ Active, Roche) was sometimes used to obtain near instant glucose values in the field and compare them to the glucose values obtained by the i-STAT Clinical Analyzer.

\section{Data compiling procedure}

We reviewed available and published health and hematological data from other Galápagos iguanas. Data were sourced primarily from two publications by Lewbart and colleagues (2015, 2019) from individuals of $C$. pallidus, C. subcristatus, the two other species of Galápagos land iguanas, and A. cristatus, the Galápagos marine iguana. The protocols used while sampling individuals of these other species are the same as those adopted for this study, in fact they 
were performed by the same author $(G L)$. For this reason, when possible, the data were used to perform inter-specific comparisons.

\section{Data analysis}

Unless otherwise stated, all statistical analyses and data manipulations were performed in $\mathrm{R}$ v4.0.5 (R Core Team 2021). We compared morphological, blood gas, and hematology parameters between pink iguana samples and, when possible, we compared these results to parameters available for other species of Galápagos iguanas. We divided the analytical procedure in two parts: intra-specific and inter-specific.

\section{Intra-specific}

We first built boxplots using SVL and mass from each individual. After removing potential outliers we calculated summary statistics (mean, standard deviation, minimum and maximum values) for these two variables while accounting for sex differences.

In 2019 we collected some hematological parameters using alternative protocols to allow a comparison between alternative methodologies. For example, we used two different iStat cartridge types (Chem8 and CG-8), and in some cases we also repeated the measurement using standard lab techniques and the use of a micro-centrifuge (see description above). This procedure allowed us to compare whether data collected using different methodologies were significantly different from each other, and we report on this below. A direct comparison between alternative methodologies was conducted using a Wilcoxon Rank Sum Test.

Linear morphological features (mass and SVL) were used to calculate an estimate of individual body condition as suggested by Peig and Green (2009). We first used the smatr Rpackage (Warton et al., 2012) to compute a scaling exponent (derived from a standardized major axis regression). This exponent was then used to calculate the Scaled Mass Index (SMI) for each individual using the following expression:

$$
S M I=M_{i}\left[L_{0} / L_{i}\right]^{b_{s m a}} \text { (after Peig and Green, 2009), }
$$

where $M_{i}$ and $L_{i}$ are the body mass and the linear body measurement of individual $i$ respectively; $b_{\text {sma }}$ is the scaling exponent estimated by the SMA regression of $M$ on $L_{;} L_{0}$ is an 
arbitrary value of $L$ (in this case we used the arithmetic mean value of SVL for the study population). We accounted for the significant difference between sexes by computing a sexspecific separate scaling exponent prior to computing the SMI for each individual. This value was used in a regression analysis using hematological and biochemical values as response variables against SMI. We looked for significant correlations using Spearman's Rank Correlation index, which is more robust when data depart from normal distribution.

\section{Inter-specific}

We compiled morphological and physiological data on Galápagos iguanas from Lewbart and colleagues $(2015,2019)$. When possible, we used this information to compare estimated values for other species with those recorded for pink iguanas.

\section{Results}

\section{Intra-specific}

We used samples collected in 2019 to assess if different types of i-Stat cartridges (CG8 and Chem8) would produce significantly different results when measuring blood parameters. We compared results for glucose, calcium, sodium, potassium and hematocrit and found no significant differences. The total number of individuals collected between 2019 and 2021 was 42. Of these, one sample escaped while handling it and, although a blood sample had been already collected, we were not able to complete the screening procedure. For this reason, we eliminated it from the analyzed data set. Table 1 shows sampling details of analyzed pink iguana individuals divided by sex and year. As every animal is uniquely tagged, we identified two individuals that were captured in both sampling seasons.

Table 1 Number of individual pink iguanas sampled on WV by sex and year (Tot. - total).

\begin{tabular}{c|c|c|c|}
\multicolumn{1}{c}{ Females } & Males & Tot. \\
\hline 2019 & 7 & 8 & 15 \\
\cline { 2 - 4 } 2021 & 16 & 10 & 26 \\
\cline { 2 - 4 } Tot. & 23 & 18 & 41 \\
\cline { 2 - 4 } & &
\end{tabular}


Summary statistic results by sex within pink iguanas are presented in Table 2 and Figures 1, 2 and 3. Morphological characteristics of adult pink iguanas analyzed here are in line with results from other studies (see for example Gentile et al., 2009), with males significantly larger and heavier than females (Wilcoxon Rank Sum Test with continuity correction p-value $<<0.01$ for SVL and for mass $<<0.01$ ). No significant sex effect was found on other variables such as heart rate, respiratory rate or temperature.

Table 2 Mean, Standard Deviation (SD), minimum value (Min), and maximum value (Max) of pink iguana morphological features and health parameters by $\operatorname{sex}(\mathrm{M}=$ male, $\mathrm{F}=$ female).

\begin{tabular}{r|c|c|c|c|c|c|c|c|}
\multicolumn{3}{c}{} & \multicolumn{2}{c|}{ Mean } & \multicolumn{2}{c|}{ Min } & \multicolumn{2}{c|}{ Max } \\
\hline & M & F & M & F & M & F & M & F \\
\cline { 2 - 9 } SVL (cm) & 47.10 & 41.60 & 4.82 & 4.53 & 37.40 & 33.60 & 60.20 & 51.80 \\
Mass (Kg) & 4.99 & 3.76 & 1.25 & 0.82 & 1.50 & 2.20 & 6.50 & 4.87 \\
\hline $\begin{array}{r}\text { HR (bpm) } \\
\text { RR (brpm) }\end{array}$ & 69.83 & 77.82 & 18.33 & 14.80 & 32.00 & 60.00 & 92.00 & 108.00 \\
\hline T ${ }^{\circ}$ C & 31.42 & 31.76 & 5.67 & 5.35 & 21.30 & 22.40 & 39.20 & 40.10 \\
\hline
\end{tabular}

All animals sampled were deemed clinically healthy based upon physical examination with the exception of one 2021 female with a marked dermatitis, likely associated with a heavy mite infestation (Figure 4). Otherwise this animal appeared to be healthy. Two animals were noted to be missing digits or parts of digits, most likely from intraspecific aggression (Figure 5). Almost all iguanas (95\%) collected between 2019 and 2021 had ticks (between 9 and 90) on various parts of their body. Ticks were collected and stored in $70 \%$ ethanol but remain in Galápagos for identification at a later time. No significant abnormalities were noted on initial examination or on review of the infrared ocular images. A representative image showing the detail captured in the photographs is presented in Figure 6. The intraocular pressure values for right $(R)$ and left $(L)$ eyes were similar and not significantly different after a Wilcoxon rank sum test with continuity correction (mean \pm standard deviation IOP_R $=7.04 \pm 2.41$; mean \pm standard deviation IOP_L $=7.50 \pm 2.17 ; \mathrm{p}$-value $=0.32$ ). Tear production $(T P)$ values for the right eye (mean \pm standard deviation TP_R $=14.2 \pm 5.22$ ) were not significantly different ( $p$-value $=$ 
0.51) for TP values of the left eye (mean \pm standard deviation TP_L = $12.9 \pm 3.66)$. No effect of sex was found on any of the general physiological parameter measured and reported (Table 2 and Figures 1 and 2). Table 3 and Figure 3 present summary statistics on all biochemical and blood parameters measured for pink iguanas. We found a significant difference between males and females only in ionized calcium values (Wilcoxon Rank Sum Test with continuity correction p-value $=0.02$ ) and total solids (Wilcoxon Rank Sum Test with continuity correction p-value $<<$ 0.01). Figure 7 shows the correlation between different variables for pink iguana individuals.

Table 3 Mean and Standard Deviation (SD) of blood biochemical parameters measured in C. marthae samples and separated according to sex ( $\mathrm{M}=$ male, $\mathrm{F}=$ female). Base excess in extracellular fluid compartment (BEECF); Glucose (Glu); Hemoglobin $(\mathrm{Hb})$; Bicarbonate $\left(\mathrm{HCO}_{3}{ }^{-}\right)$; Hematocrit $(\mathrm{HCT})$; ionized calcium (Ca); Potassium (K); Lactate; Sodium (Na); Partial pressure of carbon dioxide $\left(\mathrm{pCO}_{2}\right) ; \mathrm{pH}$ measured at standardized temperature $\left(\mathrm{pH}_{\left[37^{\circ} \mathrm{c}\right]}\right)$; Partial pressure of oxygen $\left(\mathrm{pO}_{2}\right)$; Total carbon dioxide $\left(\mathrm{tCO}_{2}\right)$; Total protein solid (TS). Variables highlighted in bold indicate there was a significant difference between males and females.

\begin{tabular}{|c|c|c|c|c|}
\hline & \multicolumn{2}{|c|}{ Mean } & \multicolumn{2}{|c|}{ SD } \\
\hline & M & $\mathbf{F}$ & M & $\mathbf{F}$ \\
\hline$B E E C F$ & -1.87 & -7.14 & 2.74 & 5.89 \\
\hline Glu (mmol/L) & 154.47 & 155.21 & 22.41 & 26.19 \\
\hline$H b(g / L)$ & 10.89 & 10.69 & 1.67 & 1.56 \\
\hline $\mathrm{HCO}_{3}^{-}(\mathrm{mmol} / \mathrm{L})$ & 22.95 & 19.18 & 2.83 & 4.32 \\
\hline HCT (\%) & 32.11 & 31.47 & 5.01 & 4.72 \\
\hline $\mathrm{Ca}(\mathrm{mmol} / \mathrm{L})$ & 1.33 & 1.45 & 0.15 & 0.15 \\
\hline$K(\mathrm{mmol} / \mathrm{L})$ & 3.64 & 3.12 & 0.85 & 1.20 \\
\hline Lactate (mmol/L) & 9.18 & 10.25 & 4.45 & 4.35 \\
\hline $\mathrm{Na}(\mathrm{mmol} / \mathrm{L})$ & 160.82 & 153.95 & 3.94 & 6.33 \\
\hline$p \mathrm{CO}_{2}(\mathrm{mmHg})$ & 27.57 & 29.92 & 7.47 & 4.88 \\
\hline$p H_{\left[37^{\circ} \mathrm{C}\right]}$ & 7.39 & 7.31 & 0.10 & 0.13 \\
\hline $\mathrm{pO}_{2}(\mathrm{mmHg})$ & 45.25 & 43.00 & 18.94 & 14.11 \\
\hline $\mathrm{tCO}_{2}(\mathrm{mmHg})$ & 23.88 & 22.91 & 3.78 & 3.98 \\
\hline$T S(g / L)$ & 7.62 & 10.22 & 1.15 & 1.65 \\
\hline
\end{tabular}

Inter-specific 
On average, body temperature and potassium levels did not differ significantly between the four species. For all other comparisons we did find some statistically significant differences (Figures 10 and 11). The respiratory rate of $A$. cristatus turned out to be lower than all species of land iguanas, with that of male $A$. cristatus significantly lower after Bonferroni correction (Figure 11). 


\section{Discussion}

The work of field biologists and veterinarians benefits from having species-specific baseline physiological values from healthy animals for parameters that can be quickly, accurately, and inexpensively measured with commercial equipment. In ectothermic reptiles, such data are especially important, owing to diverse environmental conditions and habitats. Our study provides the first blood gas, biochemistry, and hematology measures in Galápagos pink land iguanas and performs a preliminary comparison of these data with those published for other species of Galápagos iguanas. These results provide a useful baseline for veterinarians and other researchers.

Point-of-care analyzers like the i-STAT may require caution in interpretation, as published studies have found that some blood gas and hematocrit values are not always accurate or reliable with certain non-mammalian species. In rainbow trout (Onchyrhynchus mykiss) results varied with temperature and only $\mathrm{pH}$ was a uniformly reliable value (Harter et al., 2014). A study in sandbar sharks (Carcharhinus plumbeus) determined the i-STAT is not reliable for accurately measuring blood gases (Harter et al., 2015b). The i-STAT did not produce valid $\mathrm{sO}_{2}$ or hemoglobin values in the bar-headed goose (Anser indicus; Harter et al., 2015). In our case, the blood gas values and $\mathrm{pH}$ were fairly consistent between the four species, except for the much higher sodium levels in marine iguanas (Lewbart et al., 2015). This is most likely a result of the dietary and habitat difference between the terrestrial and marine iguanas. Marine iguanas also had higher potassium levels than all three land iguanas. The calcium values were comparable between all four species.

Most of the blood values we recorded for pink land iguanas were similar to those reported in other iguanids (Alberts et al., 1998; Dallwig et al., 2011; Divers et al., 1996; Harr et al., 2001; Klaphake et al., 2017; Lewbart et al., 2019; Maria et al., 2007). For example, the average PCV in green iguanas, Iguana iguana, (Harr et al., 2001) was 36.7\%, slightly higher than the average found in pink iguanas (31.75\%). This value, indeed, is more similar to values reported for the basilisk lizard (Basiliscus plumifrons, 31.4\%), and much closer to that of $C$. subcristatus (Dallwig et al., 2011; Lewbart et al., 2019). Blood sodium levels reported for green iguanas and basilisk lizards are 160 and 153.5 mmol/L, respectively (Harr et al., 2001; Dallwig et 
al., 2011), whereas the average sodium levels recorded for $C$. marthae, C. subcristatus, and $C$. pallidus are $156.9,154.0$, and $153.7 \mathrm{mmol} / \mathrm{L}$, respectively. A general and easy way to determine health status and stress is blood glucose (Martinez-Jimenez and Hernandez-Divers, 2007). Basilisk lizards (that were held in cloth bags overnight and sampled 12 hours postcapture) had a fairly high level (203 mg/dL; Dallwig et al., 2011) while C. subcristatus and C. pallidus sampled almost immediately upon capture had much lower levels (126 and $135 \mathrm{mg} / \mathrm{dL}$, respectively; Lewbart et al., 2019). The pink iguana glucose values, based on the i-STAT, average $154.9 \mathrm{mg} / \mathrm{dL}$, similar to that of captive green iguanas $(166 \mathrm{mg} / \mathrm{dL}$ for males and $180 \mathrm{mg} / \mathrm{dL}$ for females, Harr et al., 2001). Wild Allen Cays rock iguanas (Cyclura cychlura inornata) had a mean glucose of $189 \mathrm{mg} / \mathrm{dL}$ (James et al., 2006).

On the whole, the pink iguanas we examined were alert, robust, and clinically healthy. This status is supported by all indicators used in this work, with the differences between the marine and land species explained as reflecting differences in their adaptation and ecology. A general healthy status was found in C. marthae, despite high tick loads and high levels of hemoparasite (hemogregarine) infection exhibited by this species. In general, even though the highly hemoparasitized population of $C$. subcristatus from Wolf volcano did show significant alteration in some measures of immune function, significant correlation between corticosteroid levels (or body condition index) and the number of ticks or parasitemia were not found in $C$. marthae (Onorati et al., 2017). This supports the hypothesis that, in C. marthae, ecto- and hemoparasites can be sufficiently tolerated, without causing disease or inducing clinical signs such as lethargy, open-mouth breathing, weight loss, and dehydration that may be observed in immunocompromised animals (Nardini et al., 2013).

Although C. marthae seems to be in good health at present, we recommend that the only existing population be regularly monitored to track possible changes in health status that may be induced by the harsh and changing environment where the species lives. There are currently discussions by a variety of engaged conservation groups about how to best conserve and protect $C$. marthae. Some of these strategies include captive propagation, head-starting of juveniles, and translocation. If any or all of these practices are employed, having baseline data from healthy wild animals will be critically important. 


\section{Acknowledgements}

We are indebted to the park rangers of the Galápagos National Park for

their invaluable support and friendship. This work is part of a long-term institutional agreement between the University Tor Vergata and the Galápagos National Park Directorate, aimed at the conservation of Galápagos iguanas. G.C. was supported by a Post-Doctoral Research Fellowship from the San Diego Zoo Wildlife Alliance funded by a donation from the Kenneth and Anne Griffin Foundation. G.G. was supported by grants from the International Iguana Foundation and from Friends of Galápagos, Switzerland. GAL thanks Diego Páez-Rosas, Juan Pablo Muñoz-Pérez, Carlos Mena, Stephen Walsh, and the Galápagos Science Center for their assistance and support. 


\section{Figures}
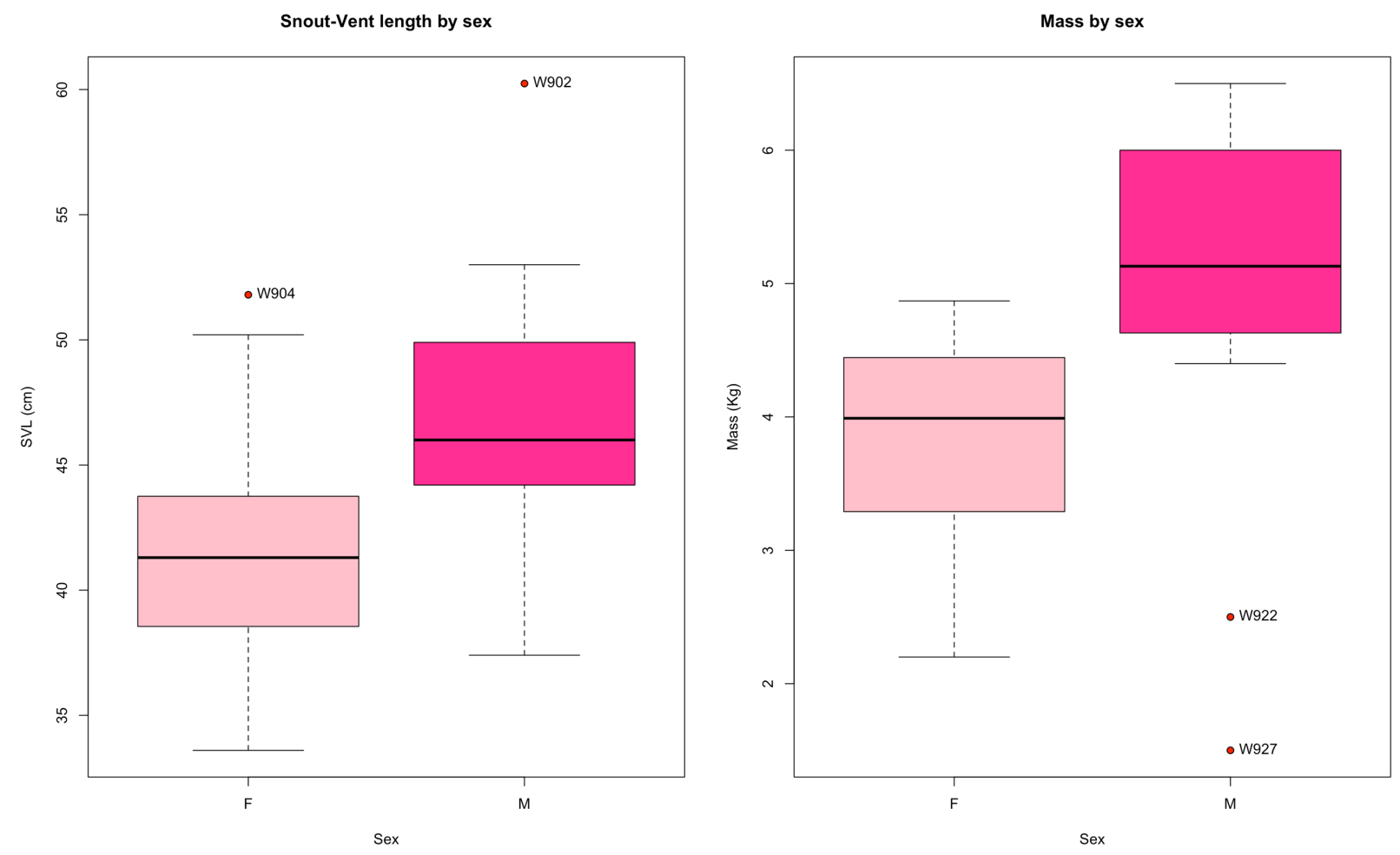

Figure 1 Boxplot representing SVL and body mass data for female (F) and male (M) pink iguanas sampled. These and following boxplots should be interpreted as follows: lower whisker edge represents minimum value; lower box edge represents $25^{\text {th }}$ percentile (Q1); black thick line represents median value; upper box edge represents $75^{\text {th }}$ percentile (Q3); upper whisker edge represents maximum value. Potential outliers are represented by red dots extending beyond the lower and upper whiskers. In all boxplots the text associated with the outliers is the field identifier code of the sampled individuals that are deemed outliers. 


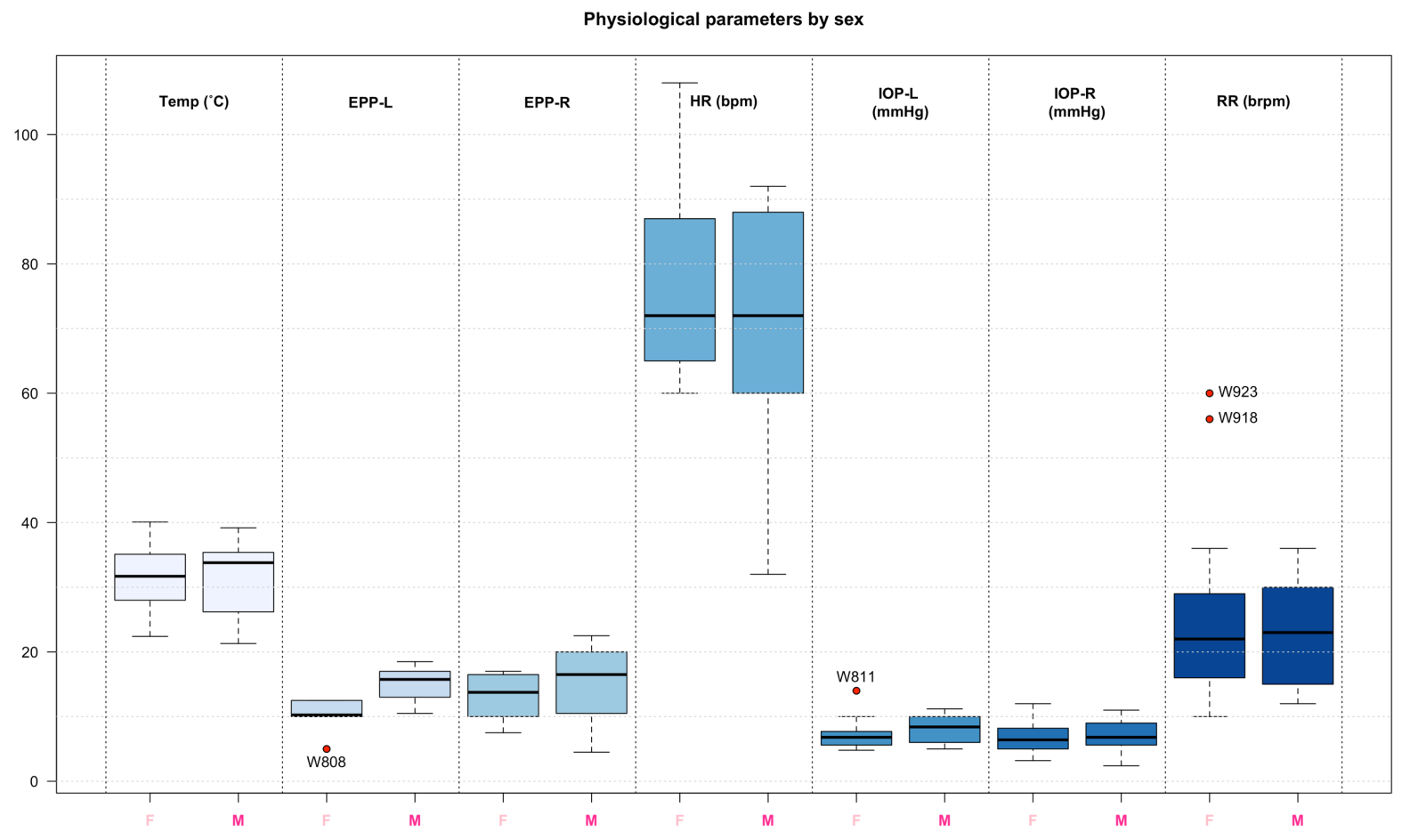

Figure 2 Boxplot comparisons of physiological parameters for female (F) and male (M) pink iguanas.

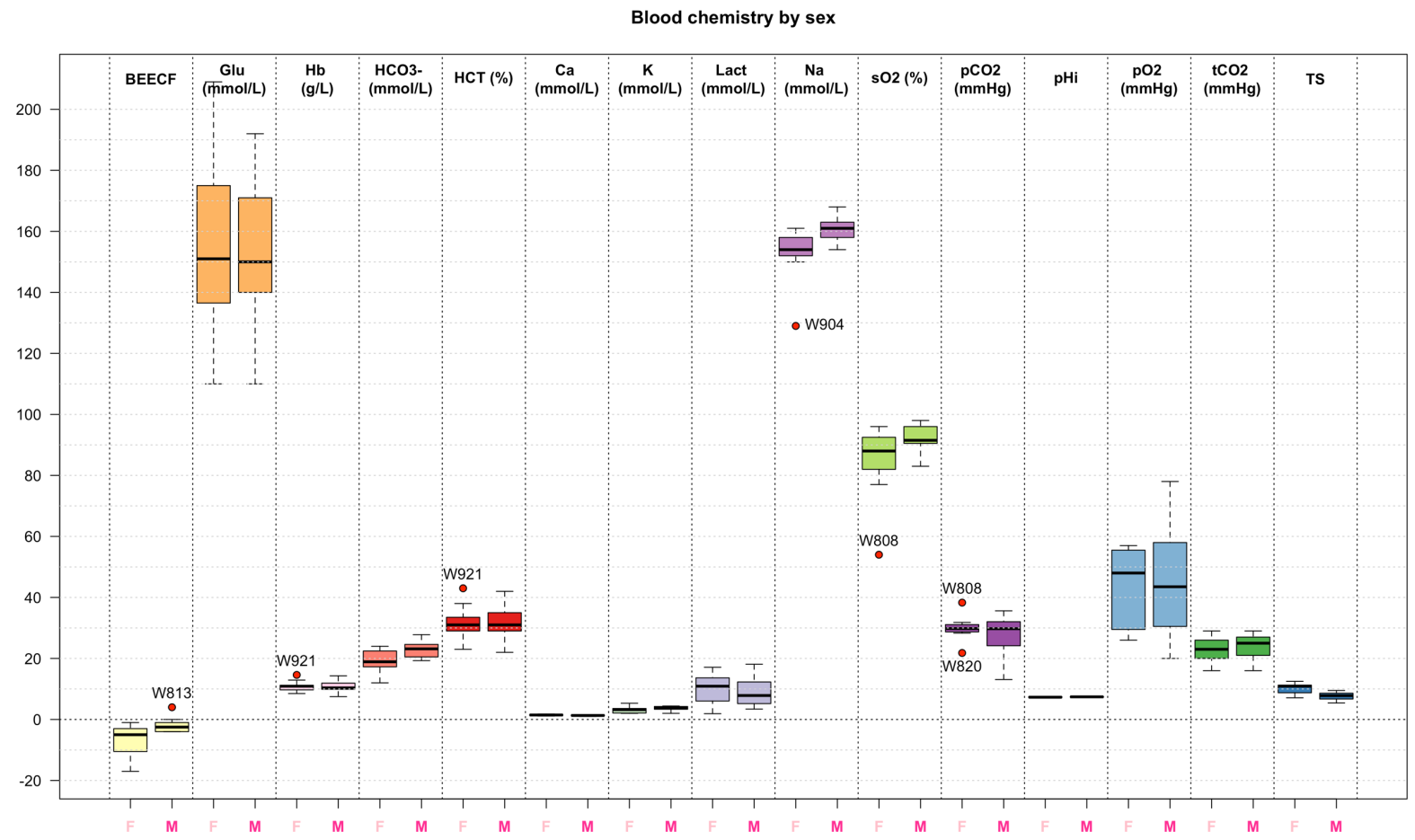

Figure 3 Boxplot comparisons of blood parameters for female (F) and male (M) pink iguanas. 

available under aCC-BY 4.0 International license.

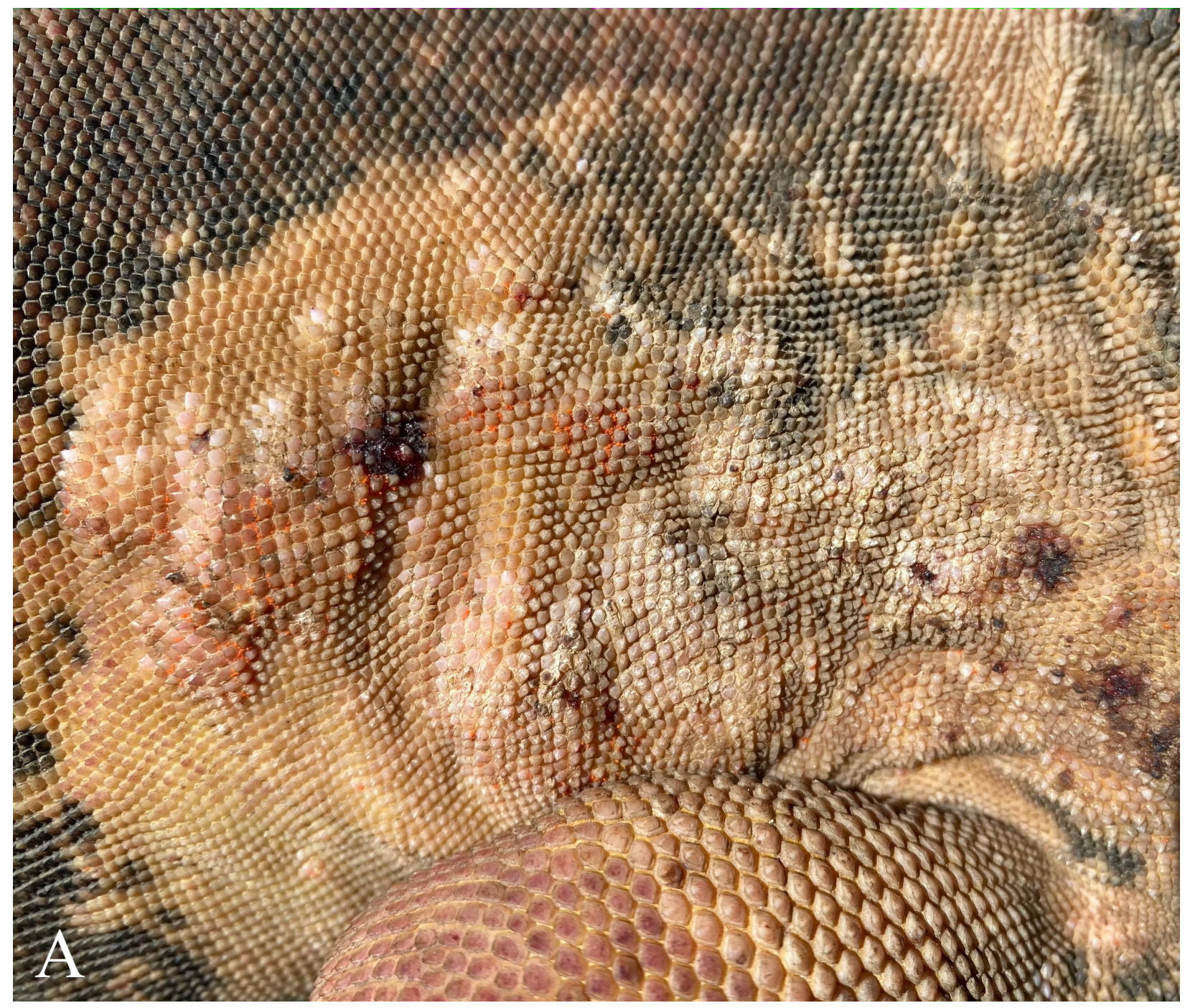


bioRxiv preprint doi: https://doi.org/10.1101/2021.08.26.457766: this version posted Auqust 27, 2021. The copyright holder for this preprint (which was not certified by peer review) is the author/funder, who has granted bioRxiv a license to display the preprint in perpetuity. It is made available under aCC-BY 4.0 International license.

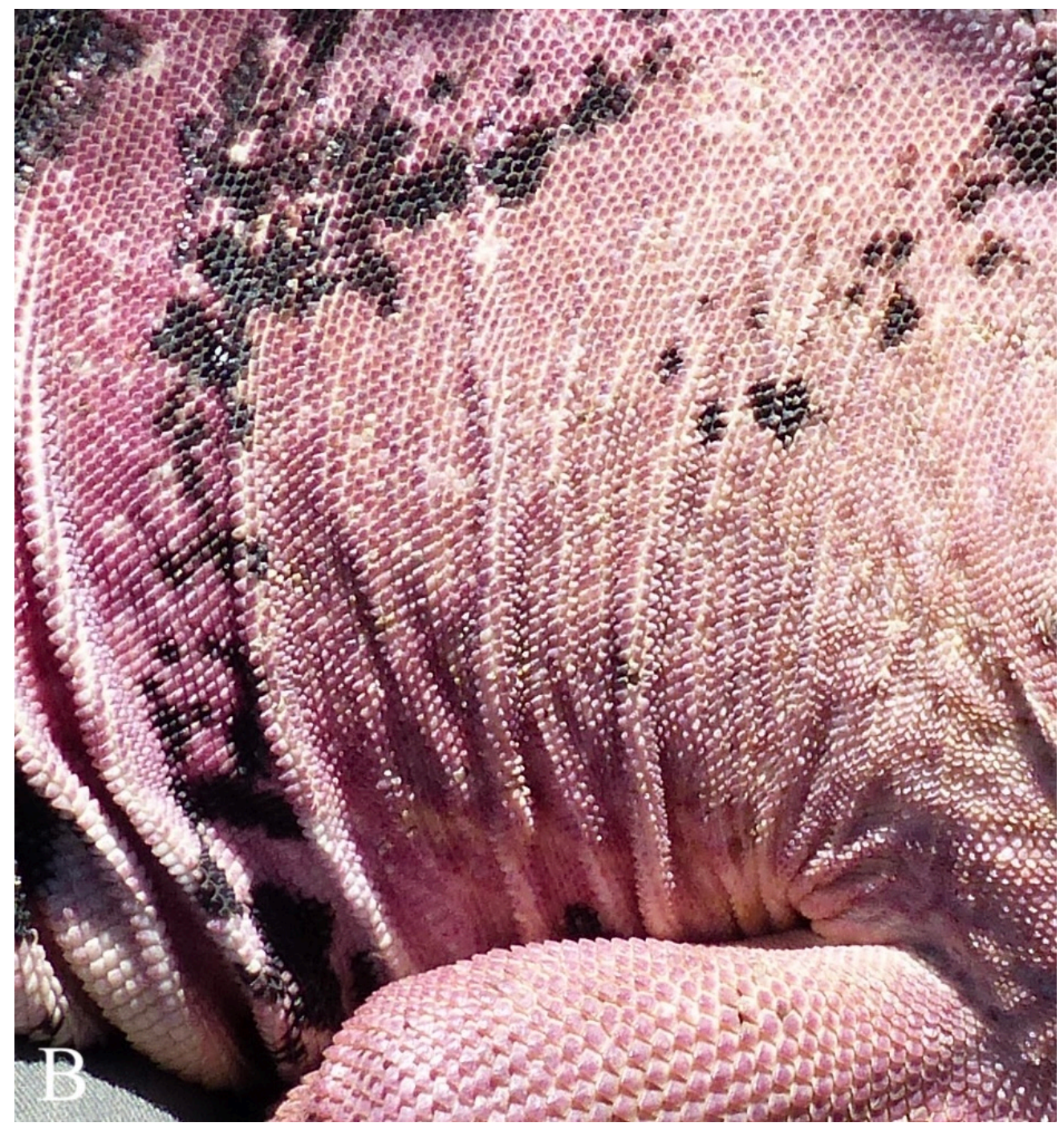

Figure 4. Right side cranial trunk and shoulder of two pink land iguanas (Conolophus marthae). A. Adult female with marked raised dermatitis and a heavy mite infestation (clusters of small orange dots). B. Adult female with normal skin and a lack of visible ectoparasites. 
bioRxiv preprint doi: https://doi.org/10.1101/2021.08.26.457766; this version posted August 27, 2021. The copyright holder for this preprint (which was not certified by peer review) is the author/funder, who has granted bioRxiv a license to display the preprint in perpetuity. It is made available under aCC-BY 4.0 International license.

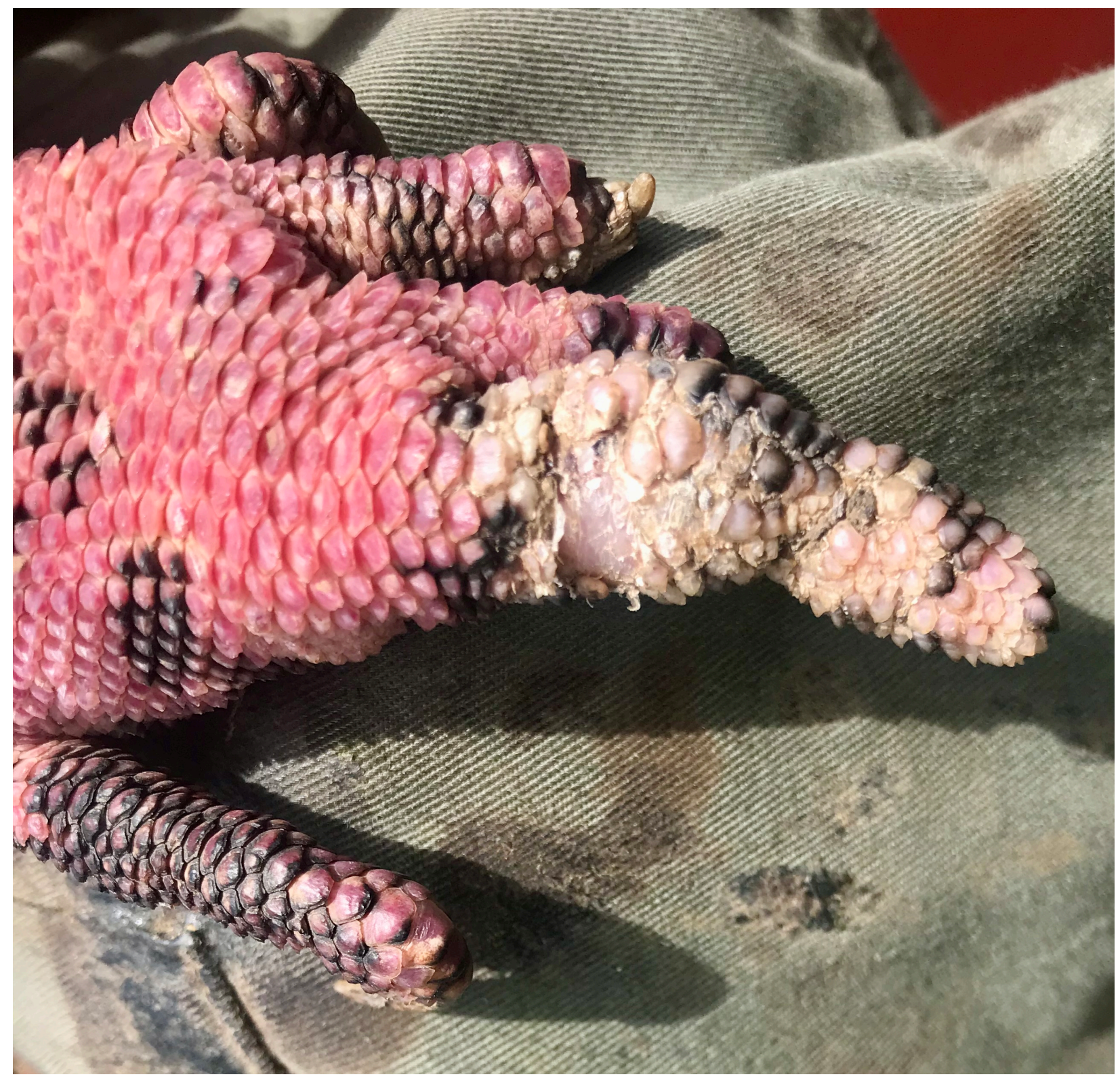

Figure 5. Hind foot of a pink land iguana (Conolophus marthae) exhibiting damaged but healed fourth digit. 
bioRxiv preprint doi: https://doi.org/10.1101/2021.08.26.457766; this version posted August 27, 2021. The copyright holder for this preprint (which was not certified by peer review) is the author/funder, who has granted bioRxiv a license to display the preprint in perpetuity. It is made available under aCC-BY 4.0 International license.

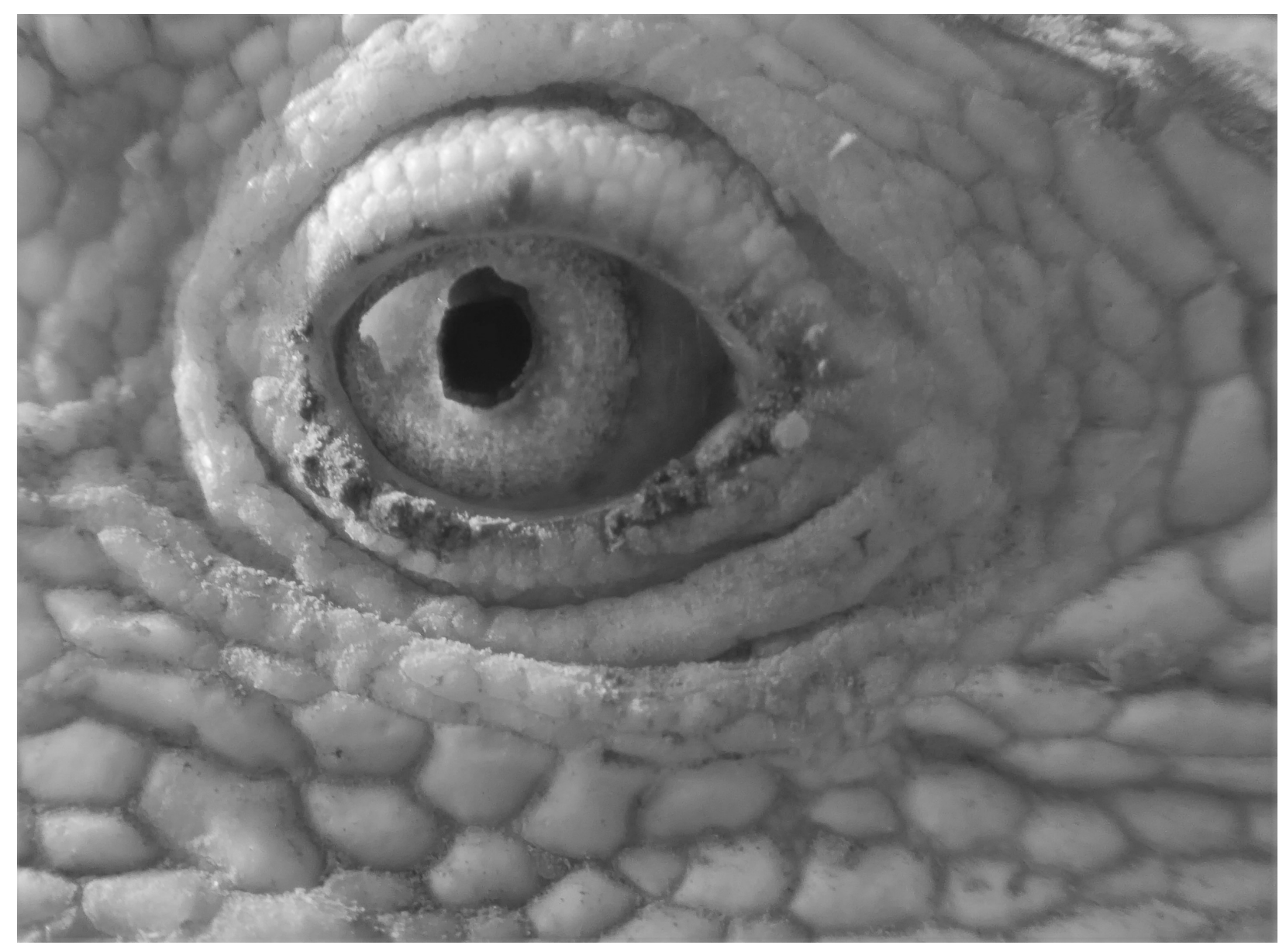

Figure 6 Example of infrared image used to analyze ocular health in pink iguana individuals. 


\begin{tabular}{|c|c|c|c|c|c|c|c|c|c|c|c|c|c|c|c|}
\hline & & & & & & & & & & & & & 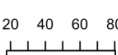 & & 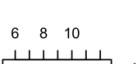 \\
\hline SN & & 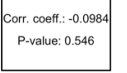 & 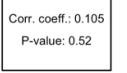 & 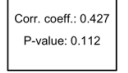 & 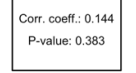 & 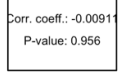 & 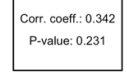 & 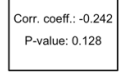 & 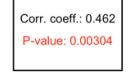 & 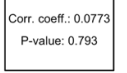 & 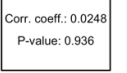 & 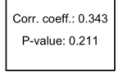 & 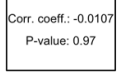 & $\mid$ & 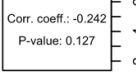 \\
\hline & & 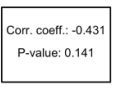 & 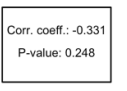 & 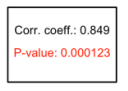 & 促 & tativents & An: 0.0964 & 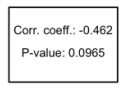 & 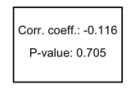 & 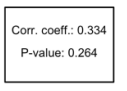 & 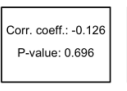 & 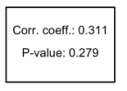 & 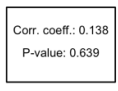 & 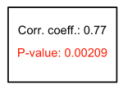 & 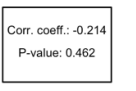 \\
\hline & & Glu & 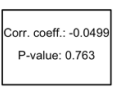 & 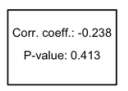 & 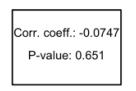 & 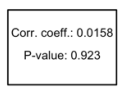 & 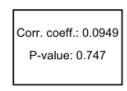 & 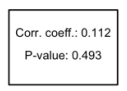 & 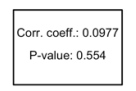 & 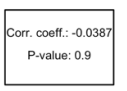 & 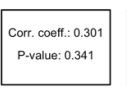 & 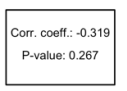 & 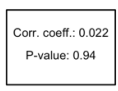 & 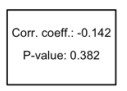 & 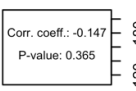 \\
\hline & & & Hb & tat: 0283 & (1: 0966 & 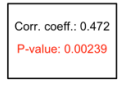 & 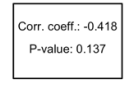 & 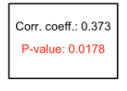 & 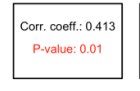 & 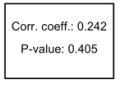 & & 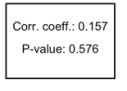 & 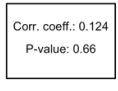 & 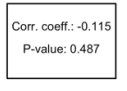 & 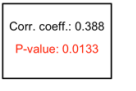 \\
\hline & & & & $\mathrm{HCO}_{3^{-}}$ & 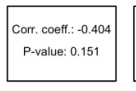 & 急 & 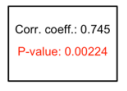 & 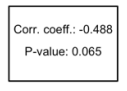 & 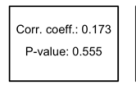 & 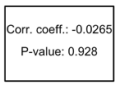 & & 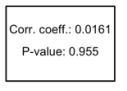 & 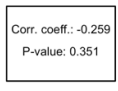 & 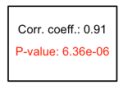 & 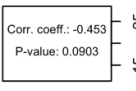 \\
\hline & & & & & HCT & 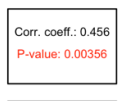 & 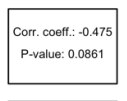 & 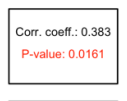 & 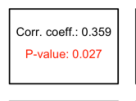 & 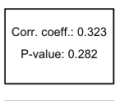 & 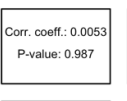 & 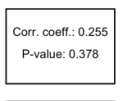 & 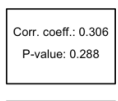 & 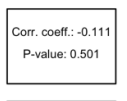 & 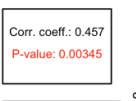 \\
\hline & & & & & & $\mathrm{Ca}$ & 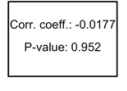 & 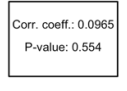 & 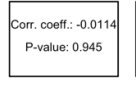 & 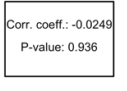 & $\mid$ & 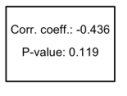 & 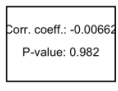 & 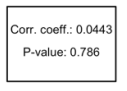 & 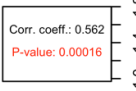 \\
\hline & & 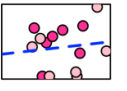 & & oged & & \begin{tabular}{ll|}
$0^{\circ}$ \\
\end{tabular} & K & 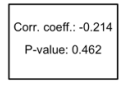 & 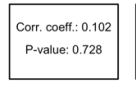 & 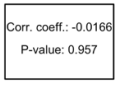 & $\mid$ & 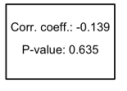 & 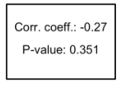 & 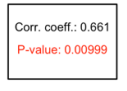 & 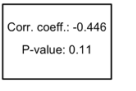 \\
\hline & & & & & & & & Lact & 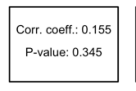 & 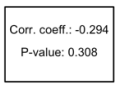 & & 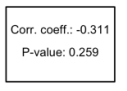 & 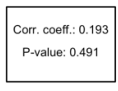 & 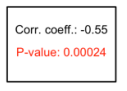 & 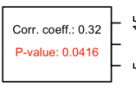 \\
\hline & & & & & & & 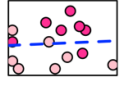 & 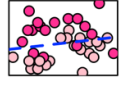 & $\mathrm{Na}$ & 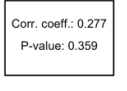 & 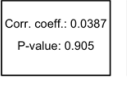 & 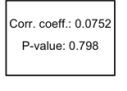 & 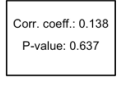 & 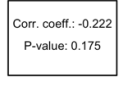 & 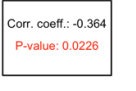 \\
\hline & & 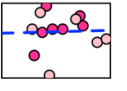 & & & & 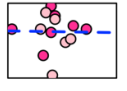 & $=0$ & & 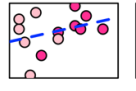 & $\mathrm{sO}_{2}$ & & 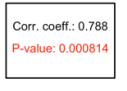 & 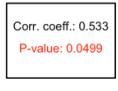 & 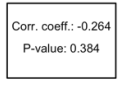 & 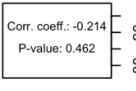 \\
\hline & & $\begin{array}{c}-20009 \\
-0 \\
0\end{array}$ & & & 280 & 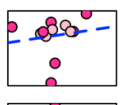 & $3-\infty \theta^{\circ}-5$ & (8)-0- & $\begin{array}{c}8080^{\circ} \\
0\end{array}$ & 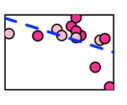 & & 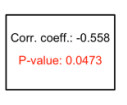 & 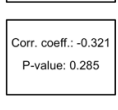 & 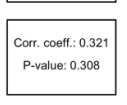 & 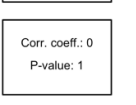 \\
\hline 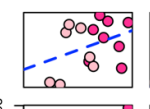 & & 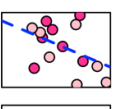 & & & & 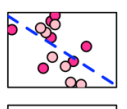 & 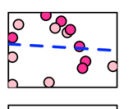 & 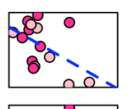 & 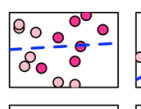 & 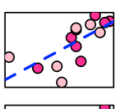 & & $\mathrm{pH}$ & 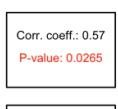 & 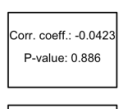 & 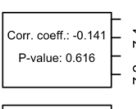 \\
\hline - & \begin{tabular}{r|r|}
-580 \\
0 & -8 \\
0
\end{tabular} & 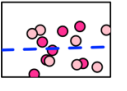 & oge- & 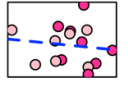 & 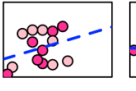 & 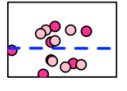 & 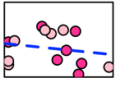 & 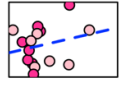 & 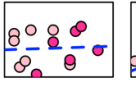 & $2=-88^{\circ}$ & $-\therefore-\frac{20}{8}$ & 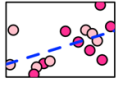 & $\mathrm{pO}_{2}$ & 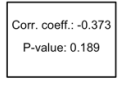 & 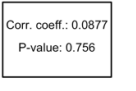 \\
\hline 0 & $5^{0}$ & व.8. & 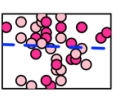 & $0^{88^{8 e^{8}}}$ & 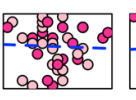 & 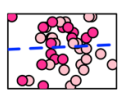 & $\begin{array}{l}0.88-9 \\
5-0^{-88} \\
0\end{array}$ & 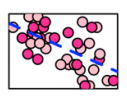 & 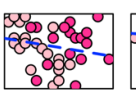 & & $=-8$ & 5 & $\frac{12}{0}$ & $\mathrm{tCO}_{2}$ & 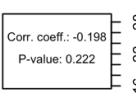 \\
\hline & & & & 152025 & 0.860 & 售 & 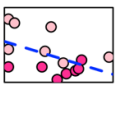 & 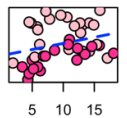 & 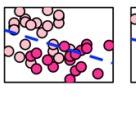 & 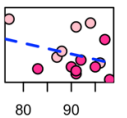 & & 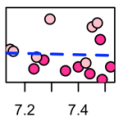 & 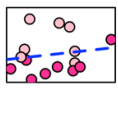 & 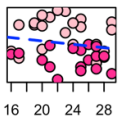 & \\
\hline
\end{tabular}


Figure 7 Spearman's Rank Correlation values estimated on linear regression lines between variables listed across the diagonal. Significant correlations are highlighted in red. 
Snout-Vent length by species and sex

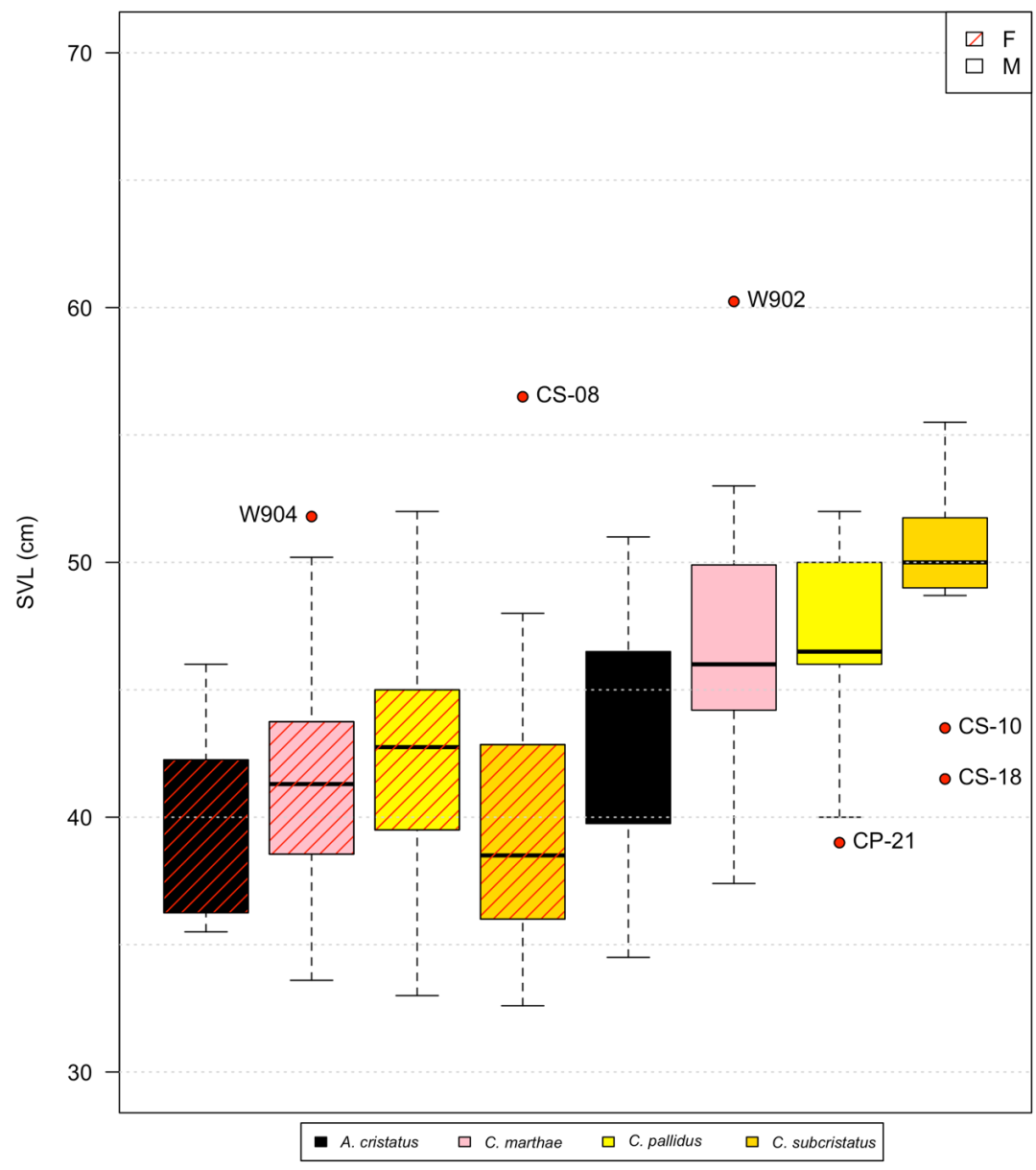

Mass by species and sex

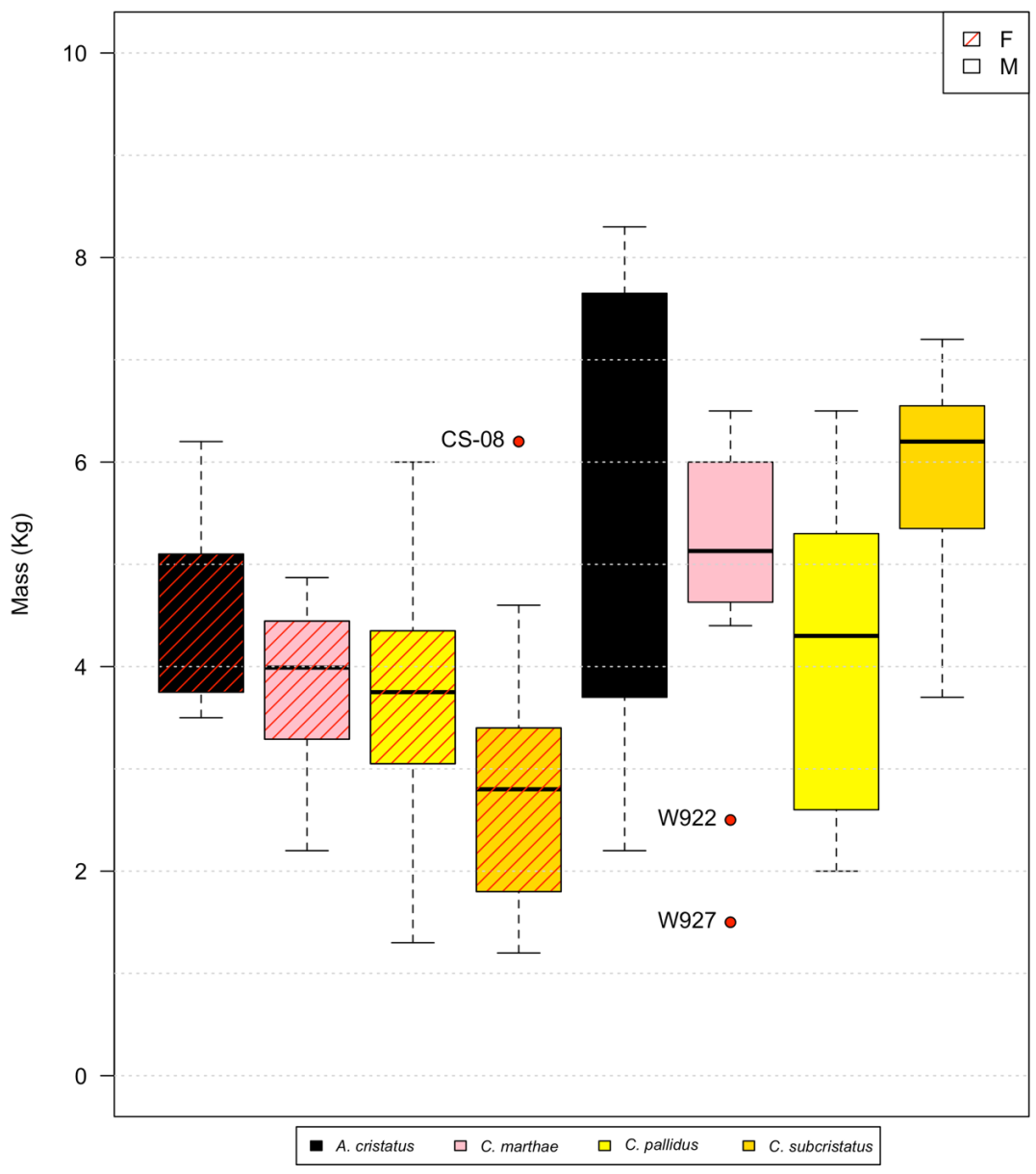


bioRxiv preprint doi: https://doi.org/10.1101/2021.08.26.457766; this version posted August 27, 2021. The copyright holder for this preprint (which was not certified by peer review) is the author/funder, who has granted bioRxiv a license to display the preprint in perpetuity. It is made available under aCC-BY 4.0 International license.

Figure 8 Boxplot comparisons of snout-vent length (SVL) and mass for sampled female (F) and male (M) iguanas by species. Box plot parameters as in Figure 1.

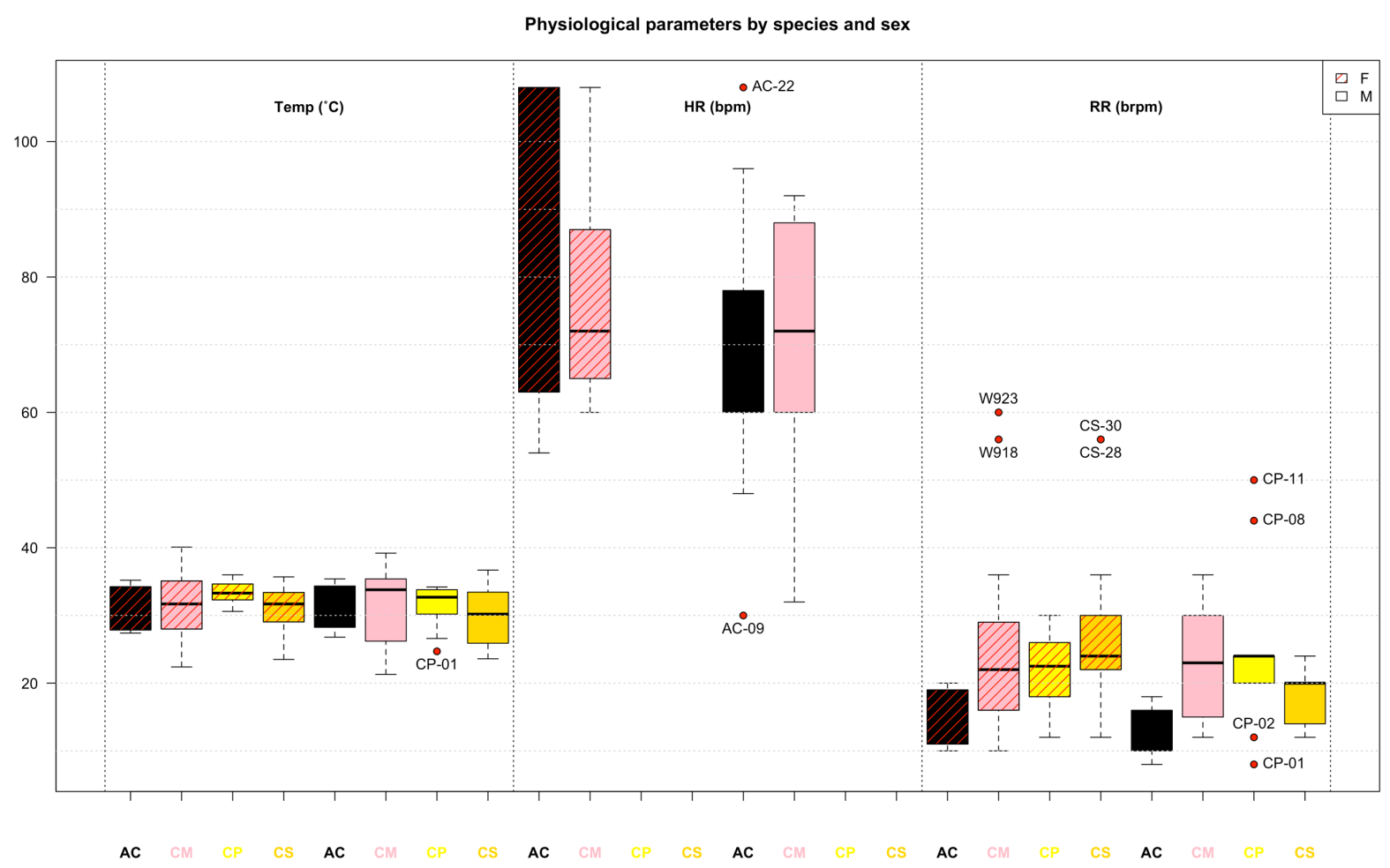

Figure 9 Boxplot comparisons of physiological parameters for sampled female (F) and male (M) iguanas by species. Box plot parameters as in Figure 1. 

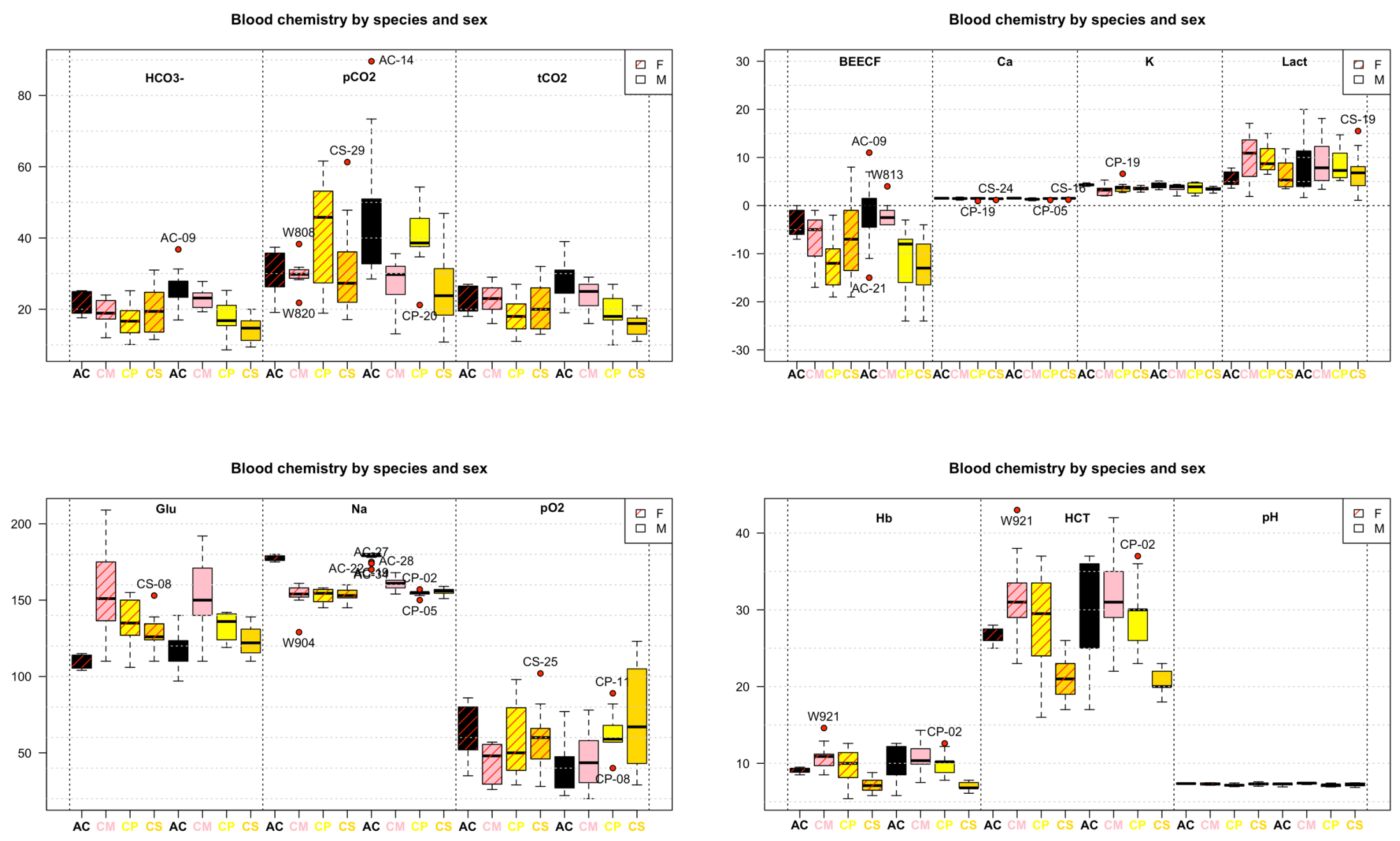

Figure 10 Boxplot comparisons of blood parameters between male and females of different iguana species. 
Pairwise Comparisons

Wilcoxon Rank Sum Test with Bonferroni Correction
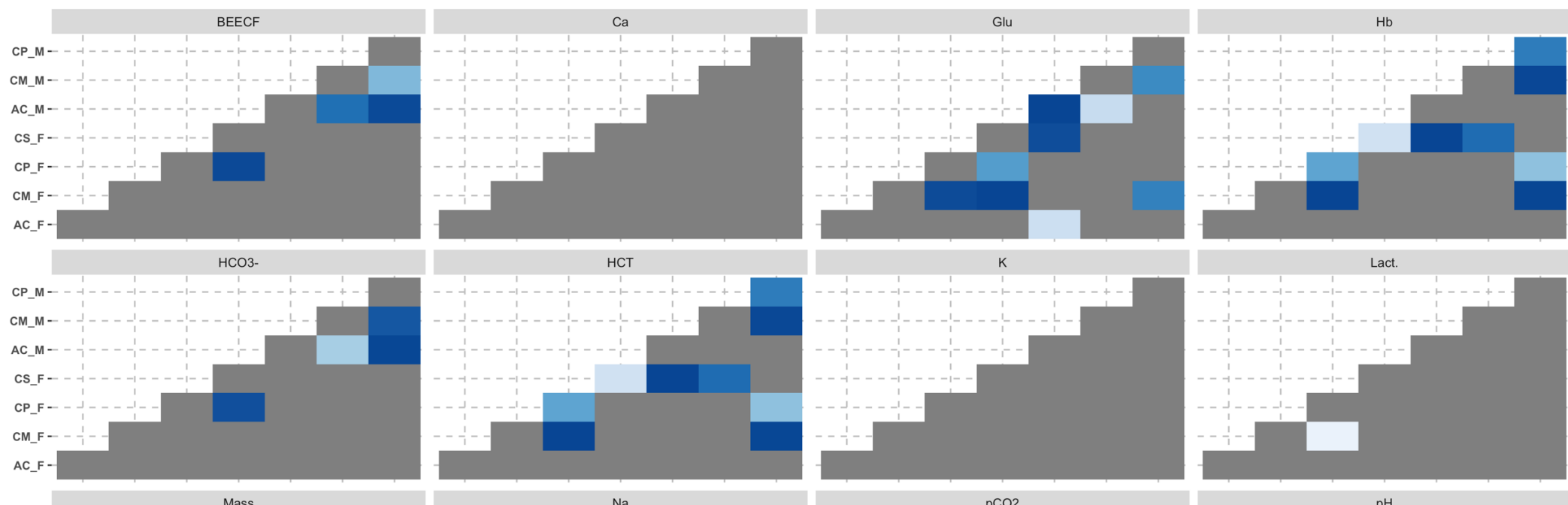

Mass

$\mathrm{Na}$
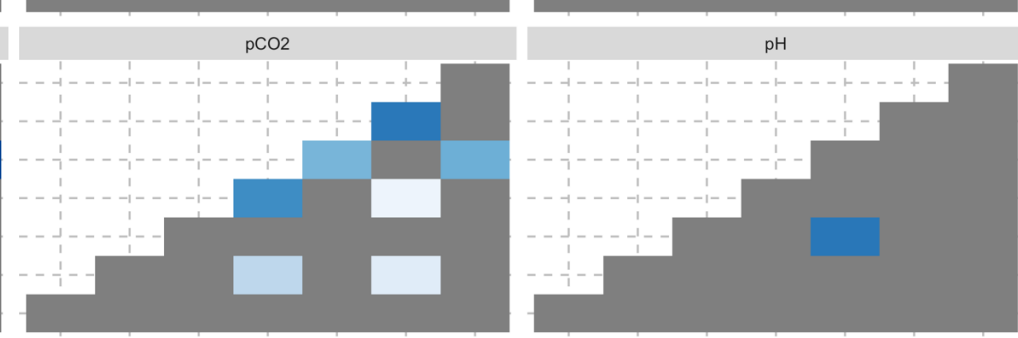

0.04

P_M

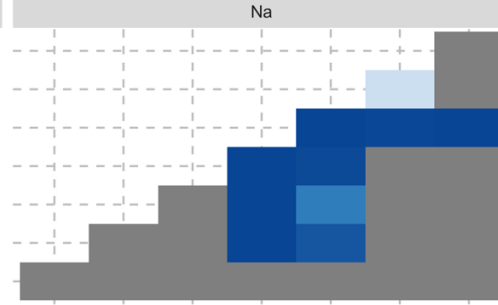

Resp. Rate
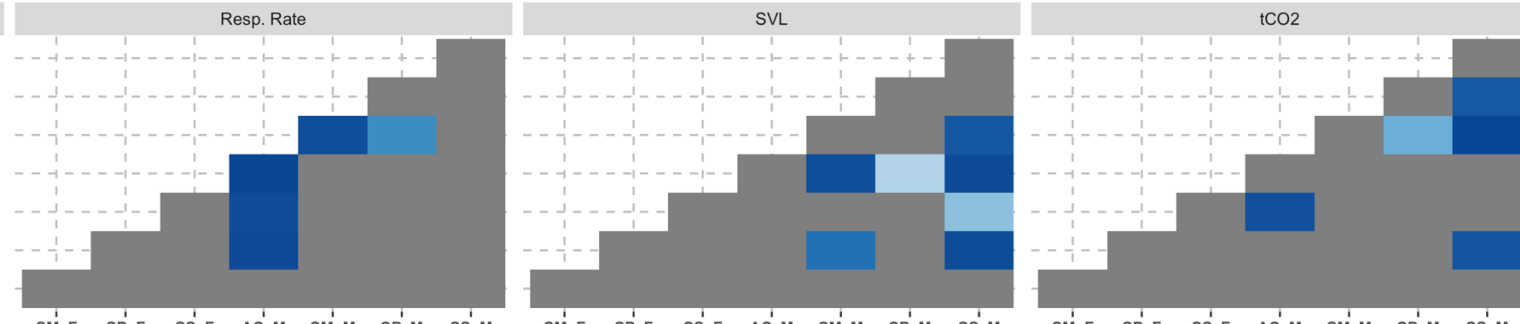

Figure 11 For each estimated parameter we looked for significant differences between species by sex. Each heatmap above shows when values differed significantly between sexes or species. P-values were adjusted for multiple comparisons using Bonferroni correction method. Darker shades of blue indicate $p$-values closer to 0. 


\section{References}

Alberts AC, Olivia ML, Worley MB, Telford SR, Morris PJ, Jannsen DL. The need for pre-release health screening in animal translocations: a case study of the Cuban iguana (Cyclura nubila). Animal Conservation 1998; 1:165-172.

Arguedas-Porras R, Lewbart GA, Deresienski D, Lohmann K, Steinberg D, Muñoz-Pérez JP, Valle CA (2018) Haematology and biochemistry of the San Cristobal Lava Lizard (Microlophus bivittatus). Conservation Physiology 6(1):10.1093/conphys/coy046

Araujo NL, Raposo ACS, Muramoto C, Santos de Meneses ÍD, Bittencourt MV, Martins Filho EF, Oriá AP. Evaluation of selected ophthalmic diagnostic tests in green iguanas (Iguana iguana). Journal of Exotic Pet Medicine, 26(3), 176-187.

Campbell TW. Avian Hematology and Cytology, $2^{\text {nd }}$ Ed. lowa State University Press, Ames, IA. 1995;7-11.

Christian KA, Porter WP, Tracy R. Core Areas within the home ranges of Galapagos land iguanas, Conolophus pallidus. Journal of Herpetology 1986; 20: 272-276.

CITES Appendices I, II and III valid from 22 June 2021. Downloaded on 10 August 2021 from https://cites.org/sites/default/files/eng/app/2021/E-Appendices-2021-06-22.pdf

Colosimo G, Di Marco G, D'Agostino A, Gismondi A, Vera CA, Gerber GP, Scardi M, Canini A, Gentile G. Chemical signatures of femoral pore secretions in two syntopic but reproductively isolated species of Galápagos land iguanas (Conolophus marthae and C. subcristatus). Scientific Reports 2020; 14314 
Dallwig RK, Paul-Murphy J, Thomas C, Medlin S, Vaughan C, Sullivan L, Sladky KK, Ramirez O, Herrera G. Hematology and clinical chemistry values of free-ranging basilisk lizards (Basiliscus plumifrons) in Costa Rica. Journal of Zoo and Wildlife Medicine 2011; 42(2):205-213.

Dennis PM, Bennet RA, Harr KE, Lock BA. Plasma concentration of ionized calcium in healthy iguanas. Journal of the American Veterinary Medical Association 2001; 219(3):326-8.

Dessauer HC. Blood chemistry of reptiles: Physiological and evolutionary aspects, p. 1-72. In C. Gans and T. S. Parsons (eds.), Biology of the Reptilia, Vol. 3. Academic Press, New York, 1970.

Di Giambattista L, Fulvo A, Fabiani A, Bonanni J, Carrión JE, Gentile G. Molecular data exclude current hybridization between iguanas Conolophus marthae and C. subcristatus on Wolf Volcano (Galápagos Islands). Conservation Genetics 2018; 19(6):1461-1469.

Divers SJ, Redmayne G, Aves EK. Hematological and biochemical values of 10 green iguanas (Iguana iguana). Vet Rec 1996; 138(9):203-5.

Fabiani A, Rosa S, Marquez C, Trucchi E, Snell HL, Snell HM, Tapia W, Gentile G. Conservation of Galápagos land iguanas: genetic monitoring and predictions of a long-term program on Isla Santa Cruz. Animal Conservation 2011; 14(4):419-429.

Geffre A, Friedricks K, Harr K, Concordet D, Trumel C, Braun J-P. Reference values: a review. Vet Clin Path 2009; 38:288-298.

Gentile G (2012). Conolophus marthae. The IUCN Red List of Threatened Species 2012: e.T174472A1414375.

Gentile G, Snell H (2009) Conolophus marthae sp. Nov. (Squamata, Iguanidae), a new species of land iguana from the Galápagos archipelago. Zootaxa 2201:1-10. 
Gentile G, Fabiani A, Marquez C, Snell HL, Snell HM, Tapia W, Sbordoni V (2009) An overlooked pink species of land iguana in the Galápagos. PNAS 106(2):507-511.

Gentile G, Marquez C, Snell HL, Tapia W, Izurieta A (2016) Conservation of a New Flagship Species: The Galápagos Pink Land Iguana. In: Angelici FM (ed). Problematic Wildlife. DOI 10.1007/978-3319-22246-2_

Geist DJ, Snell H, Snell H, Goddard C, Kurz MD. A paleogeographic model of the Galápagos Islands and biogeographical and evolutionary implications In: The Galápagos: A natural laboratory for the earth sciences. Geophysical Monograph 204 (eds Harpp KS, Mittelstaedt E, d'Ozouville N, Graham DW), pp.145-166. New Jersey: John Wiley \& Sons. 2014;

https://doi.org/10.1002/9781118852538.ch8

Harr KE, Alleman AR, Dennis PM, Maxwell LK, Lock BA, Bennett RA, Jacobson E. Morphologic and cytochemical characteristics of blood cells and hematologic and plasma biochemical reference ranges in green iguanas. J Am Vet Med Assoc 2001; 218(6):915-21.

Harter TS, Shartau RB, Baruner CJ, Farrell AP. Validation of the i-STAT system for the analysis of blood parameters in fish. Conserv Physiol 2014; 2(1):10.1093/conphys/cou037.

Harter TS, Reichert M, Brayner CJ, Milsom WK. Validation of the i-STAT and HemoCue systems for the analysis of blood parameters in the bar-headed goose, Anser indicus. Conserv Physiol 2015; 3:10.1093/conphys/cov021.

Harter TS, Morrison PR, Mandelman JW, Rummer JL, Farrell AP, Brill RW, Baruner CJ. Validation of the i-STAT system for the analy sis of blood gases and acid-base status in juvenile sandbar shark (Carcharhinus plumbeus). Conserv Physiol 2015b; 3:doi:10.1093/conphys/cov002. 
Hernandez-Divers SJ, Stahl SJ, Stedman NL, Hernandez-Divers SM, Schumacher J, Hanley CS, Wilson $\mathrm{H}$, Vidyashankar AN, Zhao Y, Rumbeiha WK. Renal evaluation in the healthy green iguana (Iguana iguana): assessment of plasma biochemistry, glomerular filtration rate, and endoscopic biopsy. J Zoo Wildl Med 2005; 36(2):155-68.

James SB, Iverson V, Raphael B. Health assessment of Allen Cays rock iguana. Cyclura cychlura inornata. J Herpetol Med Surg 2006; 16:93-97.

Klaphake E, Gibbons PM, Sladky KK, Carpenter J. Reptiles. In: Exotic Animal Formulary, 5th Edition (J. Carpenter and C. Marion eds.), Elsevier Saunders, St. Louis, MO, 2017.

Lewbart GA, Hirschfeld M, Muñoz J, Denkinger J, Vinueza L, Brothers JR, García J, Lohmann KJ. Blood gasses, biochemistry, and hematology of marine iguanas (Amblyrhynchus cristatus). Conserv Physiol 2015; 3(1): cov034; doi: 10.1093/conphys/cov034

Lewbart GA, Grijalva CJ, Calle PP, Ingerman K, Muñoz-Pérez JP, Quezada G, Vera CA, Gentile G, Valle CA. 2019. Health assessment of Conolophus subcristatus, Conolophus pallidus, and C. subcristatus X Amblyrhynchus cristatus hybrid (Galápagos land iguanas). PLoS ONE 14(10):e0222884.

Loreti P, Catini A, De Luca M, Bracciale L, Gentile G, Di Natale C. The Design of an Energy Harvesting Wireless Sensor Node for Tracking Pink Iguanas. Sensors 2019; 19(5), 985

Loreti, P., Bracciale, L., Colosimo, G., Vera, C., Gerber, G.P., De Luca, M., Gentile, G. (2020). Assessment and validation of miniaturized technology for the remote tracking of critically endangered Galápagos pink land iguana (Conolophus marthae). Animal Biotelemetry 8(1), 3

Macleod A, Rodríguez A, Vences M, Orozco-terWengel P, Garcia C, Trillmich F, Gentile G, Caccone A, Quezeda G, Steinfartz S. Hybridization masks speciation in the evolutionary history of the 
Galápagos marine iguana. Proc R Soc B 2015; 282 (1809): 20150425.

http://dx.doi.org/10.1098/rspb.2015.0425.

Maria R, Ramer J, Reichard T, Tolson PJ, Christopher MM. Biochemical reference intervals and intestinal microflora of free-ranging Ricord's iguanas (Cyclura ricordii). J Zoo Wildl Med 2007; 38(3):414-9.

Martinez-Jimenez D, Hernandez-Divers SJ. Emergency care of reptiles. Vet Clin North Am Exot Anim Pract 2007 10:557-585.

Nardini G, Leopardi S, Bielli M. Clinical hematology in reptilian species. Vet Clin North Am Exot Anim Pract 2013 16(1):1-30.

Ng WL, Short TG, Gunn KN, Fuge GS, Slon B. Accuracy and reliability of the i-STAT point-of-care device for the determination of haemoglobin concentration before and after major blood loss. Anaesth Intensive Care 2014; 42(4):495-9.

Peig J, Green AJ. New perspectives for estimating body condition from mass/length data: the scaled mass index as an alternative method. Oikos 2009; 118:1883-1891.

Peig J, Green AJ. The paradigm of body condition: a critical reappraisal of current methods based on mass and length. Funct Ecol 2010; 24:1323-1332

R Core Team. R: A language and environment for statistical computing. R Foundation for Statistical Computing. Vienna, Austria 2021: https://www.R-project.org/

Rassmann K. Evolutionary age of the Galápagos iguanas predates the age of the present Galápagos Islands. Mol Physl Evol 1997; 7:158-172. 
Rassmann K, Tautz D, Trillmich F, Gliddon C. The microevolution of the Galápagos marine iguana Amblyrhynchus cristatus assessed by nuclear and mitochondrial genetic analyses. Mol Ecol 1997a; 6:437-452.

Rassmann K, Trillmich F, Tautz D. Hybridization between the Galápagos land and marine iguana (Conolophus subcristatus and Amblyrhynchus cristatus) on Plaza Sur. J Zool Lond 1997b; 242:729-739.

Tzika AC, Rosa SF, Fabiani A, Snell HL, Snell HM, Marquez C, Tapia W, Rassmann K, Gentile G, Milinkovitch C. Population genetics of Galápagos land iguana (genus Conolophus) remnant populations. Mol Ecol 2008; 17:4943-4952.

Wagner RA, Wetzel R. Tissue and plasma enzyme activities in juvenile green iguanas. Am J Vet Res 1999; 60(2):201-203.

Warton DI, Duursma RA, Falster DS and Taskinen S. smatr 3 - an R package for estimation and inference about allometric lines. Method Ecol Evolut 2012; 3(2):257-259.

Werner D. The Galapagos Land Iguanas (Conolophus): Natural history and conservation surveys. Natl Geogr Soc Res Rep 1984; 17:81-94.

Wyles JS, Sarich VM. Are the Galápagos iguanas older than the Galápagos? Molecular evolution and colonization models for the archipelago. In Patterns of evolution in Galapagos organisms: 177-185. Bowman, RI, Berson M, Levinton AE (Eds). Am Assoc Adv Sci Pacific Div, San Francisco, 1983. 